\title{
A Fixação de Justa Indenização nas Desapropriações
}

\author{
ARNOLD WALD \\ (Advogado no Distrito Federal)
}

\begin{abstract}
()
decreto-lei n. ${ }^{\circ} 3.365$ de 21 de junho de 1941 , que regulou a desapropriação por utilidade pública, estabeleceu dois princípios jurídicos que vêm sendo discutidos por iesente jurisprudência: a fixação do valor da indenização no momento da declaração de utilidade pública e a sua limitação ao máximo de vinte vêzes o valor locativo.
\end{abstract}

Efetivamente o artigo 26 caput, determinava que:

"No valor da indenização, que será contemporâneo da declaração de utilidade pública, não se incluirão direitos de terceiros contra o expropriado".

E o artigo 27 fixava a seguinte regra:

"O Juíz indicará na sentença os fatos que motivaram o seu convencimento e deverá atender, especialmente, à estimação dos bens para efeitos fiscais; ao preço de aquisição e interêsse que dêles aufere o proprietário; à sua situação, estado de conservação, segurança; ao valor venal dos da mesma espécie, nos últimos cinco anos, e a valorização ou depreciação da área remanescente pertencente ao réu.

Parágrafo único: "Se a propriedade estiver sujeita ao impôsto predial, o quantum da indenização não será inferior a 10 nem superior a 20 vêzes o valor locativo, deduzida prèviamente a importância do impôsto, e tendo por base êsse mesmo impôsto, lançado no ano anterior ao decreto de desapropriação."

A aplicação do artigo 27 e especialmente do seu parágrafo único mereceu severas críticas, desde a elaboração do decreto. A jurisprudência procurou contornar a limitação legalmente estabelecida e, mesmo quando a reconhecia, consignava sua profunda injustiça.

Alguns acórdãos do Tribunal de Justiça do Distrito Federal e do Tribunal de São Paulo procuraram interpretar o parágrafo único pelo caput do artigo, dizendo que um dos critérios de que se poderia utilizar o juiz era o do valor locativo. Assim sendo, deveria obedecer ao limite fixado pelo parágrafo único do artigo 27. Mas, se o magistrado considerasse que a avaliação do prédio baseado no valor locativo levaria a cometer uma injustiça, ser-lhe-ia facultado recorrer a algum dos outros recursos previstos na lei (artigo 27 caput), já então independentemente do máximo de vinte vêzes o valor locativo. 
Um acórdão de 8 de outubro de 1943, proferido na apelação cível número 3.183 e referido por Themístocles CaVAlCaNTi (1) resume a tendência jurisprudencial que então surgiu, contrapondo-se à limitação legal estabelecida em matéria de indenização por desapropriações:

"O Dr. Juiz, porém, jungido às estreitezas do parágrafo único do artigo 27 do Decreto-lei n. ${ }^{\circ} 3.365$, limitou-se a homologar a oferta feita pela Prefeitura.

Tal critério, porém, já vai sendo objeto de condenação de uma jurisprudência sadia, que tem fulminado essas interpretações mui literais, aniquiladoras de lídimos interêsses, constitucionalmente garantidos.

De fato, o parágrafo único do art. 27 determina que "se a propriedade estiver sujeita ao impôsto predial, o quantum da indenização não será inferior a 10 nem superior a 20 vêzes o valor locativo, deduzida prèviamente a importância do impôsto, e tendo por base êsse mesmo impôsto, lançado no ano anterior ao decreto de desapropriação".

O ilustre Desembargador SEABRA FAgundeS' (da desapropriação no direito brasileiro", pág. 328) estabelece como uma das conseqüências dêsse dispositivo, que "em se tratando de bem sujeito a impôsto predial é limitada a ação do juiz na fixação do preço, dentro de um máximo e um mínimo".

Mas, pergunta-se: é de se acolher a tese de SEABRA FAgundes? É exato que o parágrafo único do art. 27 limita a ação do juiiz, convertendo-o quase nưm simples autômato?

Num gesto largo e decisivo, coibindo abusos que já escandalizam, a jurisprudência se vem pronunciando de um modo diverso, em conformidade aos princípios de justiça, resolvendo os casos na medida das circunstâncias de cada um dêles.

Dentre outros julgados, alguns já dêste Egrégio Tribunal e de que foi relator o eminente Sr. Desembargador HENRIQUe FIALHo, cumpre destacar o da Primeira Câmara do Tribunal de São Paulo (Acórdão de 8 de junho de 1942, Revista dos Tribunais, vol. 138. págs. 245-247) onde ficaram assente os seguintes princípios:

Esse dispositivo (parágrafo único do artigo 27) não deve ser interpretacio isoladamente, e sim em harmonia com o corpo do artigo 27 que estabelece diversos critérios para a fixação da indenização; estimação dos bens para efeitos fiscais; preço de aquisição e interêsse que dêles aufere o proprietário; situação, estado de conservação e segurança; valor venal dos da mesma espćcie, nos últimos cinco anos; valorização ou depreciação da área remanescente, peitencente ao réu. Êle só deve ser aplicado quando o critério da fixação fôr ùnicamente o da estimação dos bens para efeitos fiscais. Mas se o juiz abandona êsse critério por julgar que pode acarretar uma indenização injusta, ou seja inferior ao valor da propriedade, não se dá a sua aplicação.

Com isto se evita que haja violação do dispositivo constitucional que manda dar uma justa indenização ao expropriado".

(1) Themístocles BRandẽo Cavalcantr, Tratado de Direito Administrativo, 2,a ed., vol. VI, págs. 233-235 e "Revista de Direito Administrativo", vol. I, págs. 112, 85 e 106 . 
O Supremo Tribunal Federal não seguiu todavia a jurisprudência encetada pelos tribunais do Distrito Federal e de São Paulo. (2) A doutrina, consubstanciada nas obras de SEABRA FAGUNDES ( $D a$ desapropriação no direito brasileiro, loc. cit., e de Themístocles Cavalcanti (Tratado de Direito Administrativo, loc. cit. na nota 1) entre outras, adotou o critério legislativo, considerando que "protege a magistratura contra a maledicência, evita as especulações, permite ao juiz, geralmente alheio a essas sutilezas das bôlsas de imóveis, nortear a sua consciência e tomar como base para os seus cálculos um elemento objetivo inalterável pela sua vontade e arbítrio".

Outra corrente jurisprudencial, embora se mantivesse fiel à letra e ao espírito da lei, ressaltava nos acórdãos as conseqüências injustas a que a sua aplicação rígida levava. Destacamos êsses julgamentos por abrirem o caminho à exceção de inconstitucionalidade que posteriormente seria levantada em relação ao texto do artigo 27 parágrafo único do decreto-lei n. ${ }^{\circ} 3.365$.

Um acórdão da Quinta Câmara do Tribunal do Distrito Federal de 31 de março de 1944, julgando a apelação $n .^{\circ} 3.702$, tendo como relator o desembargador RochA LAGOA sintetizou o pensamento jurídico acêrca da matéria dominante naquela época.

"A jưrisprudência dêste Tribunal tem, reiteradamente, proclamado, constituir grave injustiça, lesiva dos direitos do proprietário, pagar-lhe o expropriante um preço que não corresponda ao valor da propriedade, no momento em que se efetua a desapropriação. No caso concreto, entretanto, se a indenização no máximo legal ainda é insuficiente para compor os prejuízos sofriชos pelos primeiros apelantes com essa desapropriação, impossível é conceder-se-lhes integral reparação, frente à rigidez do preceito legal que não permite ao julgador atribuir valor locativo do imóvel, deduzida a importância do impôsto predial." (3)

Assim, poucos são os julgados que se conformam com o texto legal. A1guns omitem apreciação de jure constituendo. Outros não aplicam o dispositivo legal por uma interpretação discutível do artigo 27 caput, ou já alegando a inconstitucionalidade do parágrafo único por ter a indenização de ser justa. Terceiro, embora aplicassem a lei manifestam um certo repúdio a limitação considerada injusta.

Pouco a pouco os votos vencidos se tornam majoritários. É interessante notar, como o assinala CARLos MEdeiros Silva, que a limitação da indenização nas desapropriações fôra admitido sem discussão no período áureo do individualismo e foi sob o domínio da carta de 1937 , limitada a propriedade pelos interêsses sociais e pelo bem comum, que teve o judiciário que apreciar a legalidade dessa limitação. Explica-se talvez a evolução jurisprudencial na matéria pela profunda valorização dos imóveis naquela época. Outra situaçảo que merece destaque é a posição da doutrina defendendo os interêsses

(2) Supremo Tribunal Federal, apelação n." 8.099 de 3-XI-1942 in "Revista de Direito Administrativo"', vol. 1, pág. 76, V. também o comentário do Dr. CARLOS MEDEIRos Silva ao acórdão da $3 .^{\mathrm{a}}$ Câmara Cível do Tribunal do Distrito Federal, na apelação 2.776 em 23-VII-1943, sendo relator o Desembargador HenRIQue FIALHo, in "Rev. de Dir. Administrativo", vol. I, págs. 85-105. 
do Estado com muito mais vigor do que os próprios juízes, contràriamente ao que acontece em geral.

A idéia da inconstitucionalidade do parágrafo único surgira no brilhante voto do Desembargador Henrique Fialho:

"Êsse é um dos casos em que, manifestamente, não pode ter aplicação o critério para fixação do quantum da indenização, estabelecido pelo parágrafo único do artigo 27 do Decreto-lei n. ${ }^{\circ} 3.365$, sob pena de não sòmente praticar-se a mais revoltante injustiça, importando em um quase confisco da propriedade, como, ainda mais, em violar flagrantemente o preceito constitucional contido no citado n. ${ }^{\circ} 14$ do art. 122 da vigente Constituição (de 1937) que determina seja paga indenização pela coisa desapropriada, e não importância evidente e escandalosamente inferior, como a que resultaria da aplicação do aludido parágrafo único do art. 27 do citado decreto, sem atender às relevantes considerações de ordem constitucional". (4)

O acórdão da Terceira Câmara de que foi relator o Desembargador Fialho é de 23 de julho de 1943, sendo subscrito pelos Desembargadores Flamínio de Rezende e Emanuel Sodré. Já em 30 de maio, todavia, a Quarta Câmara, na apelação n. ${ }^{\circ} 4.054$, sendo relator o Desembargador Oliveira Figueiredo, reconhecia que:

"O justo preço base da indenização tem de ser buscado em todos os fatores, que concorrem para o valor da propriedade.

A lei, quando adotou o critério do impôsto predial, procurou uma base presumivelmente estável na relatividade entre o impôsto predial e o preço da locação.

Mas, não se pode considerar como justo e razoável, nem mesmo consentâneo ao espírito da lei que, deflagrado um antagonismo violento entre o preço da locação e o valor do imóvel, possa aquêle prevalecer em detrimento asfixiante dêste último.

É o que acontece na época presente, em que a valorização sobe por múltiplas causas: aumento da população, escassez de habitações, desvalorização da moeda, ao passo ģue o preço da locação não pode acompanhar esta progressão ascencional, porque proibido está o aumento dos aluguéis por leis de emergência.

De forma que resulta daí um desequilibrio flagrante entre o preço da locação e o valor real do imóvel o que se reflete no impôsto que serve de base à desapropriação." (5)

Ainda em 1943, a 8 de outubro, um acórdão da 5 . $^{\text {a }}$ Câmara tem a seguinte ementa: "O critério do parágrafo único do artigo 27 não se deve aplicar quando acarretar indenização injusta", conforme voto do relator Desembargador SERPA LOPES. (6) Em sentido contrário se pronuncia um acórdão da mesma Câmara, em abril de 1944, sendo relator o Desembargador Sabóia

\footnotetext{
(4) Ibid., págs. 85-105.

(5) Ibid., pág. 110.

(6) Ibid., pág. 112 .
} 
Lima que considera constitucionalíssimas as disposięões do decreto-lei número 3.365. (7)

Vemos assim a orientação dominante na jurisprudência local ainda anteriormente à Constituição de 1946, que viria fortificar sobremaneira os defensores da inconstitucionalidade do parágrafo único do artigo 27 da lei de desapropriação.

Efetivamente, estabelece a Constituição vigente no seu artigo 141 parágrafo 16 que:

"E garantido o direito de propriedade, salvo o caso de desapropriação por necessidade de utilidade pública, ou por interêsse social, mediante prévia e justa indenização em dinheiro."

Diante do novo texto constitucional, a indenização havia pois de ser justa. O que o Desembargador HENRIQUE FIALHO procurara encontrar implicilamente no conceito de indenização estava agora explícito.

Seguindo a orientação já anteriormente traçada pelo Tribunal do Distrito Federal, a jurisprudência passou a reconhecer que o limite fixado no parágrafo único do artigo 27 era transponível.

O nosso tribunal local manteve e ampliou a sua tese na matéria. Um acórdão unânime da $5 .^{\text {a }}$ Câmara do Tribunal do Distrito de 2 de maio de 1952 , referente à apelação n. ${ }^{\circ} 11.995$, e sendo relator o Desembargador Duque Estrada, estabeleceu que:

O quantum da indenização, nos têrmos do parágrafo 16 do artigo 141 da Constituição Federal de 1946, só em cada caso pode ser fixado e deve representar o valor real da propriedade por ocasião do ato da efetiva desapropriação.

Para não haver diminuição da justa indenização, são devidos honorários de advogado, que devem ser calculados sôbre a diferença entre a quantia oferecida pela expropriante e a definitivamente fixada por sentença judiciária transitada em julgado." (8)

O Tribunal Federal de Recursos discrepou todavia da orientação dominante neste campo, considerando constitucional o referido parágrafo único e limitando assim a indenização.

O Supremo Tribunal Federal optou, ao contrário, pela inconstitucionalidade em acórdão de que foi relator o Ministro Orozimbo Nonato, no recurso extraordinário 18.791, julgado em 22 de junho de 1951, cuja ementa era a seguinte:

"Quando o critério estabelecido no parágrafo único do artigo 27 da Lei de Desapropriações não conduz ao cálculo de uma justa indenização, deve-se recorrer a outros índices constantes do mesmo diploma legal.

Os honorários de advogado, nas desapropriações, são pagos como parte integrante da justa indenização." (9)

Firmada a jurisprudência definitivamente no sentido da possibilidade de ultrapassar a indenização o limite fixado pelo parágrafo único do artigo 27, outra questão veio a ser debatida veementemente pelos nossos tribunais.

(7) Ibid., pág. 81 .

(8) "Revista Forense", vol. 152, pág. 220.

(9) Ap. "Revista Forense", vol. 146, pág. 322. 
Tratava-se, agora, de saber o momento em que devia ser calculado o valor do imóvel, ou seja de se reconhecer ou impugnar a constitucionalidade do artigo 26 da Lei de desapropriações, que manda avaliar o imóvel pelo seu valor no momento do decreto determinador da expropriação.

$\mathrm{Na}$ realidade, a indenização justa só pode ser aquela que corresponde ao valor atual do imóvel, a saber, ao seu valor no momento em que a sentença judicial é proferida. Como um lapso de tempo, algumas vêzes bastante longo, pode mediar entre os dois momentos - do decreto e da sentença - o valor do imóvel pode ter sofrido grandes variações.

O ponto importante, porque sintomático, na questão da escolha pelos tribunais do momento em que deveria ser feita a avaliação, está ligado ao pro: blema da depreciação da moeda. Já que um dos fatores essenciais que contribuem para a valorização dos imóveis é a depreciação monetária, resta saber, se, não obstante as leis de curso forçado e a proíbição das cláusulas estabilizadoras, o juiz poderá tomar em consideração a diminuição do poder aquisitivo da moeda. A discussão toma pois o aspecto seguinte: por conta de quem correrão os riscos das transformações do valor da moeda? Por conta do expropriante ou do expropriado? $\mathrm{Na}$ realidade, antes de receber o preço da indenização, o expropriado não se pode garantir contra as flutuações monetárias porque, embora existente o processo de desapropriação, o preço ainda esta nas mãos do pođer público. Pareceria, pois, lógico que a avaliação fôsse feita de acôrdo com o valor do imóvel no momento em que a sentença é proferida. Mas a questão primordial é saber se os tribunais podem reconhecer a depreciação da moeda não obstante as leis de curso forçado. Os tribunais brasileiros responderam afirmativamente a esta pergunta. Já na discussão referente ao artigo 27, um acórdão do Tribunal do Distrito Federal (apelação 4.054 já citada) reconhecia que a depreciação da moeda era um fator inegável da valorização dos imóveis. que as côrtes de justiça deviam tomar em consideração.

Em sentido contrário ao artigo 26 encontramos alguns acórdãos esclarecedores da matéria.

A 6. ${ }^{\text {a }}$ Câmara Civil do Tribunal de São Paulo decidiu ainda em 1951, em acórdão relatado pelo Desembargador Justino PINHEIRo na apelação número 49.363 :

"O valor da indenização não é o contemporâneo à data do decreto de desapropriação, mas sim o da época da perícia realizada para a verificação do seu valor.

Se a Constituição Federal, ao permitir a desapropriação, exige que esta se faça mediante justa indenização, é obvio que tal indenização jamais poderia ser justa se se quisesse subtrair um imóvel à ação normalmente valorizadora do tempo, máxime quando vários anos se passaram da data em que a đesapropriação foi decretada." (9)

Devemos assinalar de passagem que "a ação normalmente valorizadora do tempo" só pode ser referência à depreciação progressiva da moeda. O imóvel por si e, ao contrário do vinho, não valoriza cơm o tempo senão quando a moeda se deprecia.

No mesmo sentido encontramos um acórdão da Terceira Câmara do Distrito Federal de 1953: 
"Atualmente, diz o julgado carioca, é jurisprudência que a indenização deve corresponder ao justo e real valor da coisa desapropriada, no momento em que se efetiva a desapropriação de modo a não constituir diminuição injusta do patrimônio expropriado. O justo valor de uma propriedade imobiliária deve corresponder ao valor comercial, que é o valor do preço do mercado, no momento ou época em que o imóvel é avaliado.

Para atender ao preceito constitucional, que a subordina ao pagamento de justo preço, só se pode ter em vista o preço do mercado." (10)

A questão da inconstitucionalidade do artigo 26 foi levada ao Supremo Tribunal Federal em maio de 1952, manifestando-se por diminuta maioria - Excelso Pretório favorável à constitucionalidade do artigo. Os argumentos, de parte a parte, merecem ser destacados. A corrente majoritária apoiou-se no relatório do Ministro NELSON HUNGRIA que considerava o bem imóvel extra commercium desde o momento em que é decretada a desapropriação, acatando o valor histórico do prédio por atender ao interêsse social.

Os votos vencidos dos Ministros Mário Guimarães, Orozimbo Nonato, Rocha Lagoa e Ribeiro da Costa reconheceram a existência de uma incompatibilidade lógica entre os conceitos de valor histórico defendido pelo Decretolei 3.365 e cie justa indenização que a Constituição Federal manda pagar. Não esconderam que a valorização dos imóveis estava ligada à depreciação da moedá, fenômeno que a justiça não pode mais ignorar, não obstante as leis de curso forçado.

"A Constituição, esclarece o Ministro MÁrIo GuIMARÃEs, não manda pagar indenização com bașe neste ou naquele tempo, mas manda pagar indenização justa. Justa indenização é aquela igual ao justo valor do imóvel. Ora, como sabemos que a moeda se desvaloriza constantemente e nos tempos atuais mais do que outrora - a indenização que ao tempo era justa, pur corresponder ao justo valor do imóvel, pode não mais ser justa quatro ou cinco anos depois, por não mais representar então o justo valor do imóvel. Assin, por exemplo, um imóvel no valor de 100 contos, desapropriado noje, poderá valer, daqui a quatro anos, 200 contos; e se o proprietário nessa época só receber 100 contos terá realmente recebido apenas $50 \%$ da justa indenização." (11)

Vemos pois que, não obstante a decisão do Supremo Tribunal Federal por maioria ocasional, sérias dúvidas restam quanto à constitucionalidade do artigo 26. O problema é de grande alcance no campo das desapropriações. Mas as considerações a respeito da matéria nos levam ainda mais longe. Assistimos ao trabalho dos tribunais que reconhecendo a depreciação da moeda procuram defender os particulares contra os danos dela oriundos. Parece que tal atitude de nossa jurisprudência possa levá-la a aceitar como válidas certas cláusulas inseridas pelas partes em contrato para escapar aos riscos da depreciação monetária, desde que tais cláusulas não sejam diretamente fulminadas pelo Decreto-lei 23.501, de 1933. Tal evolução é sintomática e merece tôda a atenção do jurista.

(10) Apelação 21.897, acórdão de 10-IV-1953, sendo relator o Desembargador SABola Lima, in "Revista de Direito Administrativo", vol. 38, p. 229. 